\title{
Are Nutrition Professionals Involved in Nutrition Education? A Cross Sectional Study in Italy
}

\author{
Cena $\mathrm{H}^{*}$, Bazzano R, Roggi $\mathrm{C}$ and Turconi $\mathrm{G}$
}

Department of Public Health, Experimental and Forensic Medicine- Unit of Human Nutrition, University of Pavia, Pavia, Italy

*Corresponding author: Cena H, Department of Public Health, Experimental and Forensic Medicine- Unit of Human Nutrition, University of Pavia, Pavia, Italy, Fax: + 390382 987191, Tel: +39 0382 987542, E-mail: hcena@unipv.it

Citation: Cena H, Bazzano R, Roggi C, Turconi G (2015) Are Nutrition Professionals Involved in Nutrition Education? A Cross Sectional Study in Italy. J Nutr Health Sci 2(4): 401. doi: 10.15744/2393-9060.2.401

Received Date: July 22, 2015 Accepted Date: November 23, 2015 Published Date: November 25, 2015

\begin{abstract}
Nutrition education interventions reduce morbidity and mortality, costs of care and play an important role in maintaining health and quality of life. The survey was conducted to assess Italian nutrition professionals' involvement in nutrition education programs.

A questionnaire was developed and mailed to 1504 members of the two main Nutrition Italian Societies and subjects registered in our University Nutrition Courses archives.

Data from 1053 respondents were analysed. Three quarters of the respondents are females; $50 \%$ of the whole sample lives and works in Northern Italy, while $26 \%$ and $24 \%$ are employed in Central and Southern Italy respectively; $43 \%$ are Medical Doctors with a post graduate degree in Human Nutrition and Dietetics, 33\% are Nutritionists with a Biology degree and 24\% are Dietitians.

At present $56 \%$ of the whole sample is self-employed in private ambulatory care centres, $32 \%$ and $12 \%$ serve on nutrition support teams either in hospitals or in public nutrition services.

Ninety per cent spends time on nutrition education programs mainly addressed to the children and adolescents (38\%), to the adults $(33 \%)$, to the elderly (16\%) and to the pregnant women (11\%) and $2 \%$ to all the groups over reported. The whole sample equally served in public sanitary services (34\%), scholastic institutions (28\%) or private structures (38\%).

Most of the professionals are involved in nutrition education programs, nevertheless analysing our results we may assume that most professionals are not really involved in nutrition education programs but only in nutritional counselling.

Keywords: Nutrition education; Nutrition prevention; Nutrition professionals
\end{abstract}

\section{Introduction}

Evidences show that nutrition interventions reduce morbidity and mortality, costs of medical care and play an important role in maintaining health and quality of life [1]. A healthful diet promotes optimal health, growth and cognitive development in children and adolescents, contributes to the prevention of chronic diseases in adults and prevents or delays the spiral towards illness and disability in elderly [2,3]. Therefore primary prevention of chronic diseases can be accomplished by addressing a handful of modifiable behaviours, promoting health throughout the life cycle [4].

Recent studies have shown that sustainable changes may be achieved by nutrition education interventions focused on specific target groups through life span [2]. Dietary recommendations for a healthful diet across Europe recommend consumption of at least five portions of fruit and vegetables a day, reduced intakes of saturated fat and salt, and increased consumption of complex carbohydrates and fibre [2,5]. However, dietary consumption surveys show that most Europeans do not meet these guidelines $[6,7]$.

The alarming and increasing prevalence of overweight and obesity indicates that health promotion through dietary habits and lifestyle modifications remains a key point $[6,8]$. There is a need to develop and implement effective programs and policies that will result in adopting healthier diets in all ages, identifying the risk behaviours in order to target and tailor specific nutrition interventions, which should be part of nutritional surveillance projects and should also be carried out in hospitals as well as in ambulatory care clinics [9].

Nutritional professionals should take care of these interventions since most health professionals, in particular physicians, recognize that they lack the education and training in medical nutrition needed to counsel their patients and to ensure continuity of nutrition care [1,10-14]. Indeed in a previous review published in 2010 [15] aimed at describing the state of health nutrition practice in Italy, exploring the nature, role, and utility of training for nutrition professionals, emerged the need for increasing nutrition education interventions, which should therefore involve active participation and collaboration of nutrition professionals at different levels according to their University degree: Physician Nutrition Specialists (PNS), Nutritionists with a Biology degree (NB) and Dietitians (D). 
The aim of the present study was to investigate the Italian nutrition professionals' involvement in promoting health using nutrition education programs both in primary and secondary prevention in the different main areas of interest, in target population, by means of a cross sectional survey. Indeed nutrition education interventions may be delivered both to health groups with risk factors and/or familiarity predisposition to chronic degenerative pathologies aiming at preventing the disease, as well as to groups who had already developed chronic degenerative disorders aiming at controlling and counteracting the evolution of the disease.

\section{Materials and Methods}

A questionnaire was developed specifically for this study by a team of university nutrition professionals. Four dietitians working at Pavia's University were then asked to revise the instrument and to review the questions for clarity and relevance. Their suggestions were used to develop the questionnaire final version. The questionnaire was previously piloted on a sample of 52 nutrition professionals in order to further verify its comprehension, easiness and quickness to fill in, and revised accordingly, but validity and reliability were not formally tested.

The final version consisted of two sections. Section A included 8 items related to demographic data and actual professional employment. Section B included 18 items aimed at obtaining information on nutrition programs delivered by the professionals, target population, kind of nutrition intervention, methodology and results indicators used by the same professionals after their nutrition interventions.

The questionnaire was developed and e-mailed to 1504 nutrition professionals recruited from the members of two scientific nutrition societies (ADI, Italian Dietology Association and ANSISA, Italian Association of Specialists in Dietetics and Nutrition) and from the University archives among former students registered in University courses of Dietetics and Human Nutrition, in Post Doc course of Human Nutrition and Master courses. Data from all the respondents were treated anonymously. All participants had been informed of the study goals, and each participant provided written informed consent. The study was conducted in accordance with the World Medical Associations Helsinki Declaration for Human Studies and approved by the Ethics Committee of University of Pavia.

Responses form the completed questionnaires were considered and all statistical analyses were performed using SPSS statistical software package for Windows Version 18.0 (SPSS Inc., Chicago, IL, USA, 2010). Descriptive statistics as frequency distribution were calculated. Subjects' age was expressed as mean \pm standard deviation. Pearson's correlation coefficient was used to investigate the relationship between professionals' age and time involvement in nutrition intervention programs. The statistical significance level was set to $\mathrm{p}<0.05$.

\section{Results}

One thousand and fifty three professionals responded to the questionnaire (70\%). Three quarters of the respondents are females; mean age of the total sample was $45 \pm 12$ years (range $22-75$ years; C.I. 95\% 44.28-45.72).

Fifty per cent of the whole sample lives and works in the northern part of Italy, while $26 \%$ and $24 \%$ are employed in the central and southern part of Italy respectively.

Forty three per cent of them are Physician Nutrition Specialists (PNS), mainly Medical Doctors (MD) with a post graduate degree in Human Nutrition and Dietetics, 33\% are Nutritionists with a Biology degree and 24\% are Dietitians.

Sample demographic characteristics as far as age, gender, residency, university degree status, employment setting and years of involvement in nutrition practice are reported in Table 1.

Population targets, area of practice, kind of interventions and topics covered are shown in Table 2. Finally in Table 3 intervention methodology, results indicators used by the professionals and intervention outcomes are reported.

Negative correlation emerged between years of involvement in nutrition practice and active participation in nutrition intervention programs $(\mathrm{R}=-0.78 ; \mathrm{p}<0.01)$ in the whole sample. As far as the professional background is concerned Dietitians resulted more involved in Nutrition Education interventions than the other professionals.

\begin{tabular}{|l|l|l|}
\hline \multicolumn{3}{|c|}{ Characteristics } \\
\hline Age (years) & $\mathrm{n}$ & $\%$ \\
\hline \multicolumn{3}{|c|}{ Gender } \\
\hline Females & 790 & 75 \\
\hline \multicolumn{3}{|c|}{ Area of Residence } \\
\hline Northern Italy & 527 & 50 \\
\hline Centre Italy & 274 & 26 \\
\hline Southern Italy & 252 & 24 \\
\hline \multicolumn{3}{|c|}{ University degree status } \\
\hline Dietitians & 252 & 24 \\
\hline
\end{tabular}




\begin{tabular}{|c|c|c|}
\hline \multicolumn{3}{|c|}{ Characteristics } \\
\hline \multicolumn{3}{|c|}{ University degree status } \\
\hline Biologist & 347 & 33 \\
\hline Medical Doctors & 453 & 43 \\
\hline \multicolumn{3}{|c|}{ Employment setting } \\
\hline Private ambulatory care & 590 & 56 \\
\hline Hospitals & 337 & 32 \\
\hline Public nutrition services & 126 & 12 \\
\hline \multicolumn{3}{|c|}{ Years of involvement in nutrition practice } \\
\hline$<10$ years & 442 & 42 \\
\hline $10-20$ years & 285 & 27 \\
\hline$>20$ years & 326 & 31 \\
\hline
\end{tabular}

* mean \pm SD, C.I. $95 \%$ 44.28-45.72

Table 1: Sample demographic characteristics $(n=1053)$

\begin{tabular}{|c|c|c|c|c|c|c|c|}
\hline \multicolumn{8}{|c|}{ Nutrition Education practice \% } \\
\hline Population targets & & Area of practice & & Interventions & & & \\
\hline children \& adolescents & 38 & $\begin{array}{l}\text { public sanitary } \\
\text { services }\end{array}$ & 34 & preventive & 42 & & \\
\hline adults & 33 & schools & 28 & therapeutic & 28 & & \\
\hline elderly & 16 & private structures & 38 & both & 30 & & \\
\hline pregnant women & 11 & & & & & & \\
\hline all groups & 2 & & & & & & \\
\hline \multicolumn{8}{|c|}{ Topics \% } \\
\hline $\begin{array}{l}\text { Basics of Human } \\
\text { Nutrition }\end{array}$ & 38 & $\begin{array}{l}\text { Nutrition and Health } \\
\text { dietary recommen- } \\
\text { dations for: }\end{array}$ & 44 & $\begin{array}{l}\text { Food Safety } \\
\text { and Hygiene }\end{array}$ & 13 & Other & 5 \\
\hline food groups & 13 & obesity & 16 & $\begin{array}{l}\text { foodborne } \\
\text { diseases }\end{array}$ & 18 & & \\
\hline food pyramid & 13 & hypertension & 12 & $\begin{array}{l}\text { food preserva- } \\
\text { tion }\end{array}$ & 20 & & \\
\hline cooking methods & 9 & dyslipidemias & 13 & food hygiene & 20 & & \\
\hline nutrients & 12 & diabetes & 13 & food labelling & 39 & & \\
\hline energy requirements & 12 & $\begin{array}{l}\text { cardiovascular } \\
\text { diseases }\end{array}$ & 8 & other & 3 & & \\
\hline balanced diet & 14 & renal failure & 3 & & & & \\
\hline portion size & 10 & metabolic syndrome & 13 & & & & \\
\hline dietary guidelines & 16 & $\begin{array}{l}\text { gastrointestinal pa- } \\
\text { thologies }\end{array}$ & 6 & & & & \\
\hline \multirow[t]{3}{*}{ other } & 1 & cancer & 6 & & & & \\
\hline & & food allergies & 8 & & & & \\
\hline & & other & 2 & & & & \\
\hline
\end{tabular}

Table 2: Nutrition Education practice and topics

\begin{tabular}{|c|c|c|c|c|c|}
\hline \multicolumn{6}{|c|}{ Nutrition Education intervention methodology \% } \\
\hline Methodology & & $\begin{array}{c}\text { Information material } \\
\text { used }\end{array}$ & & Intervention frequency & \\
\hline individual interview & 43 & slides and videos & 30 & weekly & 13 \\
\hline lessons in class & 18 & $\begin{array}{l}\text { topic specific pam- } \\
\text { phlets }\end{array}$ & 55 & fortnightly & 15 \\
\hline $\begin{array}{l}\text { group discussion with } \\
\text { experts }\end{array}$ & 10 & web sites & 10 & monthly & 45 \\
\hline self-help groups & 22 & other & 5 & only once & 20 \\
\hline other & 7 & & & other & 7 \\
\hline
\end{tabular}




\begin{tabular}{|c|c|c|c|c|c|}
\hline \multicolumn{6}{|c|}{ Result indicators \% } \\
\hline $\begin{array}{l}\text { Use of result } \\
\text { indicators }\end{array}$ & & $\begin{array}{l}\text { Kind of result } \\
\text { indicators used }\end{array}$ & & \multicolumn{2}{|c|}{ Intervention outcomes } \\
\hline yes & 57 & $\begin{array}{l}\text { self-reported question- } \\
\text { naires }\end{array}$ & 15 & $\begin{array}{l}\text { increased nutrition } \\
\text { knowledge }\end{array}$ & 27 \\
\hline no & 38 & interviews & 12 & behaviour change & 3 \\
\hline \multirow[t]{4}{*}{ sometimes } & 5 & $\begin{array}{l}\text { anthropometric meas- } \\
\text { urements }\end{array}$ & 31 & $\begin{array}{l}\text { positive biochemical out- } \\
\text { comes }\end{array}$ & 9 \\
\hline & & biochemical analysis & 29 & $\begin{array}{l}\text { positive anthropometric } \\
\text { outcomes }\end{array}$ & 13 \\
\hline & & drawings and games & 10 & none & 48 \\
\hline & & other & 3 & & \\
\hline
\end{tabular}

Table 3: Nutrition Education intervention methodology and result indicators

\section{Discussion}

This study was conducted to assess Italian nutritionists' involvement in nutrition education programs since lifestyle modifications in dietary habits are reached through long term target specific education interventions both in primary and secondary prevention.

The percentage of the respondents to this survey is high (70\%) and therefore useful to draw a picture of the nutrition education involvement of the different professionals.

Three quarters of the respondents are females in line with the increasing prevalence of female students in sanitary graduate courses, observed for the last decades in Italy. The age range is wide including just graduates as well as close to retirement professionals. Most of them are Medical Doctors (MD) since the two Associations include mostly MD among their associate members. More than $50 \%$ of the sample involved in nutrition education programs is self-employed in private ambulatory care centres suggesting that most professionals have greater opportunities in organizing and managing educational programs on individual as well as group basis.

In acute care settings, best nutrition practices have been shown to improve patient outcomes and reduce health care costs [16]. Nevertheless a previous study [15], describing the state of health nutrition practice in Italy, suggested that the public health nutrition workforce and infrastructures lack the necessary capacity to respond to national population needs regarding food and nutrition at many levels. Besides it outlined the need for improved nutrition education interventions promoting health and dietary changes.

As would be expected most professionals deal with counselling and nutrition education programs for all age target groups at different levels, both in primary and secondary prevention. Besides the negative correlation between years of involvement in nutrition practice and participation in nutrition intervention programs suggests that the youngest professionals are most likely to devote themselves to education intervention programs.

As supposed, primary prevention interventions are more prevalent given that there is a lack of professionals who could devote to these programs in secondary nutritional education approaches in public and private hospitals.

Metabolic disorders and cardiovascular diseases are the main areas of interventions, reflecting the high prevalence rate of these conditions in industrialized countries $[17,18]$.

Analysing the intervention methods, frequency of interventions, materials used and the lack of long term results indicators, we may assume that mostly professionals are not really involved in nutrition education programs but only in nutritional counselling.

Back in 1997 the FAO Expert Consultation regarding Nutrition education for the public [19] underlined that nutrition education is based on the sound application of knowledge derived from the food and nutrition sciences about the relationships between diet and health [20].

The use of educators with training in nutrition, comprehending both food and Nutritional science, allows efficient use of human resources, competent to provide appropriate educational messages. Nutrition education is effective only when the path grows through knowledge to the know-how, reaching awareness.

Overall, the professionals reported no significant intervention outcomes, and this limit has already been outlined by other authors [3,21-24]. Our results showed that very few interventions have reached a behavioural change (9\%) that should be, indeed, the final aim of any education program. Among those who reported positive outcomes increased nutrition knowledge seems the more frequently achieved (27\%).

Many factors might have limited the successful outcome such as insufficient contact, short interventions, insensitive result indicators, drop out, and inadequate methodology. Age and target group did not appear to be related to the outcomes obtained. 
From these results it may be assumed that the main outcome seems to be a higher degree of nutrition knowledge rather than concepts assimilation and lifestyles change of the participants. We think that active interaction between participants and nutrition professionals should be awaited in order to implement knowledge with know-how, reaching self-awarness [3,25].

Improving the transfer of nutrition care to patients in different sets (i.e. from the in-patients care centres to the community) is fundamental to expand population health now a days when increasing chronic diseases related to aging, lifestyle, obesity and diabetes contribute dramatically to public health challenges and associated health care costs [26].

Dietitians and nutritional professionals are required to address nutrition-related conditions using best practices. This might presume an increased need for specific training aimed at managing all aspects of the nutrition education programs and developing education competencies in order to improve health care practice, patient outcomes and education, as well as population health. As Kris-Etherton, et al. (2014) [26] suggest, the need to evolve and teach evidence-based standards for nutritional care is recommended. Moreover, a multidisciplinary team educational approach should be required to realize best practice and patient outcome as demanded by society needs.

Behaviour changes are founded on motivation comprehension of target groups and effective communication. In addition social support as well as technological devices and network should be taken into account, alongside interpersonal methods, to improve chances for success.

Since providing nutrition education to motivated persons is generally more successful [27], additional efforts should be done on each person's perception of his/her chance of developing a condition, and of how serious the condition and its consequences would be, as motivating factors for behaviour changes [3]. Good nutrition and appropriate lifestyle habits must start early in life to achieve a healthy condition through life span.

This study presents few limits that must be acknowledged. More detailed questions could have been included in the questionnaire to provide further information on performance indicators, with a consequent disadvantage in time spent for its compilation. Besides we have not been able to reach all the nutrition professionals in Italy. Despite this limit the study shows some strength. Indeed this is the first study in Italy investigating nutritional education interventions undertaken by nutrition professionals.

\section{Conclusions}

Nutrition professionals should be trained on designing specific interventions, aimed at changing effectively nutrition behaviour at long term. The ultimate goal of nutrition education programs is to transfer acquired knowledge to groups so individuals can make conscious choices about their diet and lifestyle to achieve and maintain good health.

The results of this study outlined the need to focus on research methodology training for Nutritionists and Dietitians in health care aimed at achieving sustainable changes and studying the consequences of these changes at long term.

Raising awareness of the role of nutrition in chronic degenerative diseases prevention and management could contribute to target well-constructed intervention programs, develop and evaluate the impact of these programs as already pointed out by other authors.

Only applying a strict methodology we may verify the long lasting changes of nutrition education programs on dietary behaviour, biochemical variables and health through life span.

\section{Acknowledgments}

The authors thank Dr Mariangela Morelli for her help in data collection and analysis.

\section{Questionnaire}

\section{References}

1. Lenders CM, Deen DD, Bistrian B, Edwards MS, Seidner DL, et al. (2014) Residency and specialties training in nutrition: a call for action. Am J Clin Nutr 1174-83.

2. Van Cauwenberghe E, Maes L, Spittaels H, van Lenthe FJ, Brug J, et al. (2010) Effectiveness of school-based interventions in Europe to promote healthy nutrition in children and adolescents: systematic review of published and 'grey' literature. Br J Nutr 103: 781-97.

3. Sahyoun NR, Pratt CA, Anderson A (2004) Evaluation of nutrition education interventions for older adults: a proposed framework. J Am Diet Assoc 104: 58-69.

4. Ford ES, Bergmann MM, Boeing H, Li C, Capewell S (2012) Healthy lifestyle behaviors and all-cause mortality among adults in the United States. Prev Med 55: $23-7$.

5. Brug J, Oenema A (2006) Healthful nutrition promotion in Europe: goals, target populations, and strategies. Patient Educ Couns 63: 255-7.

6. Branca F, Nikogosian H, Lobstein T (2007) The Challenge of Obesity in the WHO European Region and the Strategies for Response. Copenhagen: World Health Organization.

7. The European health report 2012: charting the way to well-being World Health Organization 2013 Copenhagen $\emptyset$, Denmark.

8. Commission of the European Communities (2005) Green paper: 'Promoting Healthy Diets and Physical Activity: A European Dimension for The Prevention of Overweight, Obesity and Chronic Diseases'. Brussels: Commission of the European Communities.

9. Brug J (2008) Determinants of healthy eating: motivation, abilities and environmental opportunities. Fam Pract 25: 50-5. 
10. Adams KM, Kohlmeier M, Powell M, Zeisel SH (2010) Nutrition in medicine: nutrition education for medical students and residents. Nutr Clin Pract 25: 471-80.

11. Martinez JA, Koyama T, Acra S, Mascarenhas MR, Shulman RJ (2012) Nutrition education for pediatric gastroenterology, hepatology, and nutrition fellows: survey of NASPGHAN fellowship training programs. J Pediatr Gastroenterol Nutr 55: 131-5.

12. Castro MG, Pompilio CE, Horie LM, Verotti CC, Waitzberg DL (2012) Education program on medical nutrition and length of stay of critically ill patients. Clin Nutr 32: 1061-6.

13. McMahon MM, Hurley DL, Mechanick JI, Handelsman Y (2012) American Association of Clinical Endocrinologists' position statement on clinical nutrition and health promotion in endocrinology. Endo Pract 18: 633-41.

14. Delegge MH, Alger-Mayer S, Van Way CW 3rd, Gramlich L (2010) Specialty residency training in medical nutrition education: history and proposal for improvement. J Parenter Enteral Nutr 34: 47-56.

15. Cena H, Roggi C, Lucchin L, Turconi G (2010) Health nutrition practice in Italy. Nutr Rev 68: 556-63.

16. Rosen BS, Maddox PJ, Ray N (2013) A position paper on how cost and quality reforms are changing healthcare in America: focus on nutrition. J Parenter Enteral Nutr 37: 796-801.

17. Stocks T, Bjorge T, Ulmer H, Manjer J, Häggström C, et al. (2015) Metabolic risk score and cancer risk: pooled analysis of seven cohorts. Int J Epidemiol pii: dyv001.

18. Jardim TV, Sousa AL, Povoa TR, Barroso WS, Chinem B, et al. (2014) Comparison of cardiovascular risk factors in different areas of health care over a 20-year period. Arq Bras Cardiol 103: 493-501.

19. FAO. Nutrition education for the public: discussion papers of the FAO Expert Consultation. Rome: Food and Agriculture Organization of the United Nations, 1997.

20. Anderson JEL (1994) What should be next for nutrition education? J Nutr 124: 1828-32.

21. Elshaw EB, Young EA, Saunders MJ, McGurn WC, Lopez LC (1994) Utilizing a 24-hour dietary recall and culturally specific diabetes education in Mexican Americans with diabetes. Diabetes Educ 20: 228-35.

22. Ives DG, Kuller LH, Traven ND (1993) Use and outcomes of a cholesterol-lowering intervention for rural elderly subjects. Am J Prev Med 9: $274-81$.

23. Mayeda C, Anderson J (1993) Evaluating the effectiveness of the "Self-CARE for a healthy heart" program with older adults. J Nutr Elder 13: 11-22.

24. Crockett SJ, Heller KE, Skauge LH, Merkel, JM (1992) Mailed-home nutrition education for rural seniors: a pilot study. J Nutr Educ 24: $312-15$.

25. Taylor-Davis S, Smiciklas-Wright H, Warland R, Warland R, Achterberg C (2000) Responses of older adults to theory-based nutrition newsletters. J Am Diet Assoc 100: 656-64.

26. Kris-Etherton P, Akabas SR, Bales CW, Bistrian B, Braun L, et al. (2014) The need to advance nutrition education in the training of health care professionals and recommended research to evaluate implementation and effectiveness. Am J Clin Nutr 99: 1153-66.

27. Marcus AC, Heimendinger J, Wolfe P, Fairclough D, Rimer BK, et al. (2001) A randomized trial of a brief intervention to increase fruit and vegetable intake: a replication study among callers to the CIS. Prev Med 33: 204-16.

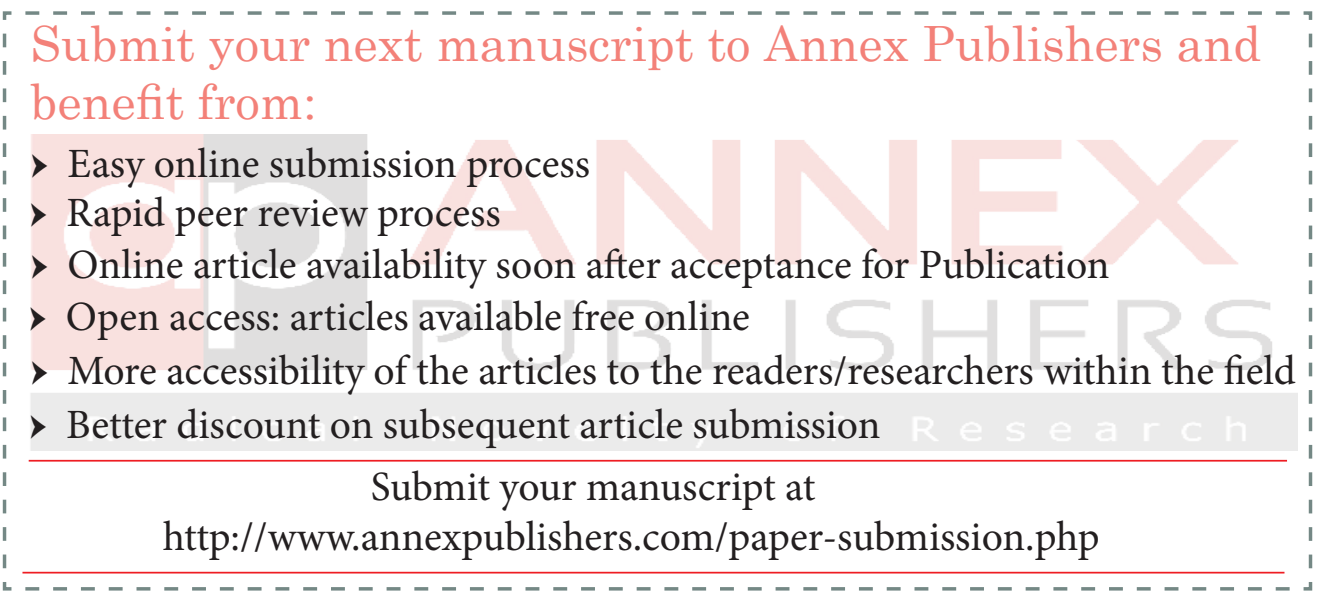

